\title{
Associations between obesity and serum lipid soluble micronutrients among premenopausal women
}

\author{
Weiwen Chai ${ }^{1}$, Shannon M. Conroy ${ }^{1}$, Gertraud Maskarinec ${ }^{1}$, Adrian A. Franke ${ }^{1}$, Ian S. \\ Pagano $^{1}$, and Robert V. Cooney ${ }^{1}$ \\ ${ }^{1}$ Cancer Research Center of Hawaii, University of Hawaii, 1236 Lauhala Street, Honolulu, HI 96813
}

\begin{abstract}
Elucidating potential pathways that micronutrients may reduce/promote chronic disease may contribute to our understanding of the underlying etiology of disease and their utility as markers of risk. In the current study, we examined associations of serum lipid soluble micronutrients with body mass index (BMI). We hypothesized that obesity may differentially influence serum micronutrient levels, thereby affecting risk for chronic disease incidence and mortality. Baseline serum samples from 180 premenopausal women from a nutritional trial were analyzed for leptin, C-reactive protein (CRP), 25-hydroxyvitamin D (25(OH)D), carotenoids, and tocopherols. Participants were stratified into normal weight (18.5-24.9), overweight (25-29.9), and obese ( $\geq 30)$ subgroups by BMI (kg/ $\mathrm{m}^{12}$ ). Differences in serum biomarkers among BMI subgroups were adjusted for Asian ethnicity and smoking status. As expected, obese individuals had significantly higher serum levels of leptin and CRP (P's < 0.05) compared to normal weight women. $\gamma$-Tocopherol levels were significantly higher in obese individuals ( $\mathrm{P}<0.05$ ), while $\alpha$-tocopherol levels did not differ among BMI subgroups. Serum levels of 25(OH)D and carotenoids (except lycopene) were significantly lower in obese than in normal weight women (P's < 0.05). The associations between BMI and carotenoids were independent of dietary intake. The obesity-associated reduction for total pro-vitamin A carotenoids (45\%) was approximately 3 -fold greater than that observed for non pro-vitamin A carotenoids (16\%). Our results indicate potential influences of obesity on serum levels of lipid soluble micronutrients and suggest that metabolism of pro-vitamin A carotenoids may contribute to the differences observed.
\end{abstract}

\section{Keywords}

Obesity; BMI; lipid soluble micronutrients; CRP; premenopausal women

\section{Introduction}

Obesity is associated with increased risk of heart disease [1], diabetes [2], and cancer [3]. The mechanism(s) by which obesity may alter cancer risk is not clearly understood, however, research has suggested that fat accumulation could contribute to chronic systemic inflammation [4] which may be a critical component of tumor progression [5]. Modifiers such as micronutrients may reduce the damaging effects of inflammation and, therefore reduce the risk

(C) 2010 Elsevier Inc. All rights reserved.

Correspondence author Weiwen Chai Cancer Research Center of Hawaii 1236 Lauhala Street Honolulu, HI 96813 wchai@crch.hawaii.edu (808) 564-5823 (808) 586-2982 (Fax).

Publisher's Disclaimer: This is a PDF file of an unedited manuscript that has been accepted for publication. As a service to our customers we are providing this early version of the manuscript. The manuscript will undergo copyediting, typesetting, and review of the resulting proof before it is published in its final citable form. Please note that during the production process errors may be discovered which could affect the content, and all legal disclaimers that apply to the journal pertain. 
associated with obesity. Suggestive associations between BMI (body mass index) and lipid soluble micronutrients, such as vitamin D, carotenoids, and tocopherols, have been reported previously $[4,6-8]$. These micronutrients play critical roles in metabolism and the maintenance of tissue functions and have been linked with cancer incidence in epidemiologic studies [9, 10]. Understanding the potential determinants of serum levels of lipid soluble micronutrients is essential to elucidating their function with respect to reducing/promoting chronic diseases as well as their utility as markers of risk.

There has been considerable research effort into the potential protective effects of carotenoids and vitamin D against chronic diseases [11,12]; however, little is known about the regulation of these micronutrients in vivo. While serum levels of carotenoids partially reflect dietary intake [13], other physiologic factors may also determine the absorption, transportation, storage, and utilization of carotenoids. 25-hydroxyvitamin D (25(OH)D) levels in plasma have been used to assess vitamin $\mathrm{D}$ status, yet determinants of its status independent of sun exposure and dietary intake are poorly understood. Lower levels of $25(\mathrm{OH}) \mathrm{D}$ have been observed among obese adults and children $[14,15]$; however, no clear explanation for this association has been published.

The primary objective of the current study was to assess the associations of serum lipid soluble micronutrients (particularly vitamin $\mathrm{D}$, carotenoids, $\alpha$ - and $\gamma$-tocopherols) with BMI to indentify unique attributes of serum micronutrients responsible for observed associations. We hypothesized that obesity may differentially influence serum micronutrient levels, thereby affecting risk for disease incidence and mortality.

\section{Methods and Materials}

\subsection{Subjects and study design}

The study protocol was approved by the institutional Review Board of the University of Hawaii. Written informed consent and permission for using stored samples for future analysis were obtained from all participants. As described previously [16], 220 females aged 35 to 46 years were randomly assigned to either the soy intervention or the control group. A validated food frequency questionnaire [17] completed by participants at baseline was used for dietary assessment. The baseline data and serum samples were used in the current cross sectional study as the effect of soy intervention was not of interest; BMI and biomarkers were available for 180 participants (we excluded 3 underweight participants from the study population).

\subsection{Sample analysis}

Serum samples were extracted and subsequently analyzed for carotenoids ( $\alpha$-carotene, $\beta$ carotene, $\alpha$-cryptoxanthin, $\beta$-cryptoxanthin, lycopene, lutein, lutein/zeaxanthin, and anhydrolutein) and tocopherols ( $\alpha$-tocopherol and $\gamma$-tocopherol) by reverse phase high pressure liquid chromatography (HPLC) with photodiode array detection between $220-600 \mathrm{~nm}$ as previously described $[18,19]$. In brief, an aliquot of $0.30 \mathrm{ml}$ of serum was mixed with $0.30 \mathrm{ml}$ ethanol containing butylate hydroxytoluene as antioxidant and 3 internal standards (tocol, retinyl laurate, and n-butyl- $\beta$-apo- $8^{\prime}$-carotenoate), followed by partitioning into $0.8 \mathrm{ml}$ hexane. The hexane layer was evaporated in amber vials at room temperature under a stream of nitrogen. The dry extracts were re-dissolved in $0.15 \mathrm{ml}$ HPLC mobile phase. The separation for carotenoids and tocopherols was performed on a Spherex ODS analytical and guard column with a mobile phase consisting of $\mathrm{MeOH}, \mathrm{CHCl}_{2}, \mathrm{MeCN}$, Bis-trispropane, and butylated hydroxytoluene. Accuracy was regularly validated through the analysis of external standards within each sample batch and through participation in the quality assurance program organized by U.S. National Institute of Standards and Technology (Gaithersburg, MD) [20]. 
Serum 25(OH)D was measured according to the manufacturer's directions using a doubleantibody enzyme-linked immunosorbent essay (ELISA) kit (Immunodiagnostic Systems, Ltd., Fountain Hills, AZ). ELISA kits purchased from R\&D System (Minneapolis, MN) were used to analyze leptin levels. The C-reactive protein (CRP) assay was based on a latex particle enhanced immunoturbidimetric method using a Cobas MiraPlus clinical autoanalyser and a kit from Point Scientific, Inc (Lincoln Park, MI).

\subsection{Statistical analyses}

Participants were stratified into the following subgroups by BMI $\left(\mathrm{kg} / \mathrm{m}^{2}\right)$ : normal weight $(18.5$ - 24.9); overweight (25-29.9); and obese ( $\geq 30$ ). Differences in serum levels of micronutrients, CRP, leptin, and dietary energy and carotenoid intakes between BMI subgroups were tested using analysis of variance (ANOVA). In order to have statistical power $=80 \%$, a total of 159 subjects were needed for ANOVA with a three-group variable, assuming a medium effect size ( $\mathrm{f}=0.25$ ) and alpha $=0.05$ (two-tailed). The model was adjusted for Asian ethnicity and smoking status (current smoker versus current non-smoker). BMI subgroup differences in serum carotenoids were additionally adjusted for nutrient density (dietary intake of respective carotenoids / dietary total energy intake x 1000; [21]) to determine whether the differences could be partially explained by dietary intake.

The associations between serum biomarkers and BMI were also assessed by Pearson correlation (r). Student's t-test was used to assess ethnicity differences (Asians versus Caucasians) and a BMI-adjusted model was also examined. SAS software (SAS Institute, Cary, $\mathrm{NC}$ ) was used for all statistical analyses and all $\mathrm{P}$ values $<0.05$ were considered statistically significant.

\section{Results}

Participants mean age and BMI were $43.0 \pm 2.9$ years and $26.3 \pm 5.7 \mathrm{~kg} / \mathrm{m}^{2}$, respectively. 40.6 $\%$ were Asians, $36.7 \%$ were Caucasians, and only $6.1 \%$ were current smokers. BMI, leptin, $\mathrm{CRP}$, and 25(OH)D were significantly lower in Asians than in Caucasians. Asians also had significantly higher serum levels of $\alpha$ - and $\beta$-cryptoxanthin and total pro- and non provitamin A carotenoids compared to Caucasians (Table 1). After adjusting for BMI, significant ethnic differences remained for CRP $(\mathrm{P}<0.05)$ and $25(\mathrm{OH}) \mathrm{D}(\mathrm{P}<0.05)$.

BMI was positively associated with serum levels of leptin $(\mathrm{r}=0.78, \mathrm{P}<0.0001)$, CRP $(\mathrm{r}=$ $0.51, \mathrm{P}<0.0001)$, and $\gamma$-tocopherol $(\mathrm{r}=0.25, \mathrm{P}=0.0008)$, and inversely associated with 25 $(\mathrm{OH}) \mathrm{D}(\mathrm{r}=-0.24, \mathrm{P}=0.0009)$ and carotenoids $[\alpha$-carotene $(\mathrm{r}=-0.26, \mathrm{P}=0.0004), \beta$-carotene $(\mathrm{r}=-0.31, \mathrm{P}<0.0001), \alpha$ - cryptoxanthin $(\mathrm{r}=-0.40, \mathrm{P}<0.0001), \beta$-cryptoxanthin $(\mathrm{r}=-0.29$, $\mathrm{P}=0.0002)$, and trans lutein $(\mathrm{r}=-0.23, \mathrm{P}=0.002)]$. As shown in Table 2 , significantly higher leptin, CRP, and $\gamma$-tocopherol, and lower 25(OH)D and carotenoids ( $\alpha$-carotene, $\beta$-carotene, $\alpha$-cryptoxanthin, $\beta$-cryptoxanthin, and trans lutein) were also observed in obese individuals after adjustment for Asian ethnicity and smoking status ( $\mathrm{P}$ 's $<0.05)$.

Although total levels of both pro-vitamin A ( $\alpha$-carotene $+\beta$-carotene $+\beta$-cryptoxanthin) and non pro-vitamin A (lycopene + lutein/zeaxanthin $+\alpha$-cryptoxanthin + anhydrolutein) carotenoids were significantly lower in obese individuals, the difference (obese versus normal weight) was considerably greater for pro-vitamin A carotenoids with $45 \%$ reduction observed in the obese subgroup. The reduction for non pro-vitamin A carotenoids was only $16 \%$ (Table 2). $\alpha$-Tocopherol and lycopene levels did not differ among BMI subgroups.

No significant differences were detected in dietary intakes of total energy $(\mathrm{P}=0.32), \alpha$-carotene $(\mathrm{P}=0.14), \beta$-carotene $(\mathrm{P}=0.25)$, lycopene $(\mathrm{P}=0.31), \beta$-cryptoxanthin $(\mathrm{P}=0.37)$, and lutein $(\mathrm{P}=0.09)$ across $\mathrm{BMI}$ subgroups. The differences in serum $\alpha$-carotene, $\beta$-carotene, $\beta$ - 
cryptoxanthin, and trans lutein between BMI subgroups persisted after adjustment for nutrient density (Table 2).

\section{Discussion}

In our study, serum levels of $\gamma$-tocopherol were significantly higher, and $25(\mathrm{OH}) \mathrm{D}$ and carotenoids, particularly pro-vitamin A carotenoids were significantly lower in the obese subgroup. The differences in serum carotenoids between BMI subgroups persisted after adjustment for nutrient density, indicating the effect of BMI on serum caroteniods was independent of dietary intake. Furthermore, the ethnic differences disappeared (except for CRP and 25(OH)D) after adjusting for BMI, suggesting that BMI may be more relevant to serum levels of lipid soluble micronutrients than ethnicity. Our results are consistent with the hypothesis that obesity differentially influences serum micronutrient levels.

Our findings were in agreement with Andersen et al. [6] who reported a strong inverse association between BMI and carotenoids ( $\alpha$-carotene, $\beta$-carotene, $\beta$-cryptoxanthin, and lutein/ zeaxanthin) among non-smokers, both cross-sectionally and longitudinally. Obesity is associated with chronic inflammation generating oxidative stress [4], and this was confirmed by our observation that serum CRP (indicator of systemic inflammation) levels were elevated in the obese subgroup. The state of chronic inflammation may be an important determinant of serum levels of lipid soluble micronutrients. With respect to serum carotenoids, interestingly, the obese subgroup had an average concentration of total pro-vitamin A carotenoids ( $\alpha$-carotene $+\beta$-carotene $+\beta$-cryptoxanthin) that was $45 \%$ lower than that observed for normal weight subgroup. In contrast, serum levels of total non pro-vitamin A carotenoids (lycopene + lutein/ zeaxanthin $+\alpha$-cryptoxanthin + anhydrolutein) were reduced only by $16 \%$. Since there were no significant differences in dietary intakes of total energy and carotenoids across BMI subgroups, it is unlikely that the differential pattern observed for pro- and non-provitamin A carotenoids was due to lack of intake. Vitamin A has been recognized for the favorable effect on immune response to infections and antioxidant action [22]. Thus, chronic inflammation associated with obesity (indicted by elevated CRP levels in obese individuals in our study) may lead to a greater requirement for vitamin A, resulting in enhanced metabolism of provitamin A carotenoids. The smaller changes in serum levels for the non pro-vitamin A carotenoids may reflect the loss of carotenoids due to higher oxidation in obese individuals. As a consequence, the lower levels of carotenoids observed in obese individuals may be a reflection of two separate processes, metabolism of carotenoids to vitamin A for immune function and the more generalized function of carotenoids as antioxidants.

The levels of serum $\gamma$-tocopherol were significantly higher in the obese subgroup in our study, whereas no significant BMI subgroup differences were observed in serum $\alpha$-tocopherol levels. $\gamma$-Tocopherol, unlike $\alpha$-tocopherol, possesses anti-inflammatory activity [23] and its levels are observed to rise in response to inflammatory signals $[24,25]$. Therefore, the elevated serum $\gamma-$ tocopherol levels in OB individuals may signify a response to systemic inflammation associated with obesity.

Consistent with previous reports $[14,15]$, we observed significantly lower mean serum $25(\mathrm{OH})$ $\mathrm{D}$ levels in the obese subgroup. Obese individuals may be exposed to less sunlight, and therefore, have lower levels of vitamin D. In a random population based sample of 367 subjects aged 25-70 years, Kull et al. [26] found lower sunbathing habits in obese than non-obese individuals. On the other hand, the lower vitamin D may be attributed to metabolic differences. Wortsman et al. [27] found substantially lower circulating 25(OH)D levels in obese adults taking supplemental vitamin D and exposed to UV light than non-obese matched controls, suggesting different pathways in the metabolism of vitamin $\mathrm{D}$ and/or its precursors by obesity level. Our results for pro-vitamin A carotenoids suggest that there may be an increased need 
for vitamin A in obese individuals due to inflammation. Vitamin A and D receptors are structurally related [28] and both molecules have been shown to have crucial effects on the immune response [29]; therefore, another possible explanation is that obese individuals may also have an increased need for vitamin $\mathrm{D}$, metabolizing it to the active form more readily, and depleting plasma levels of the precursor vitamin D species.

Our study was limited due to its cross sectional design, preventing us from determining unequivocally the causations of the observed associations. However, our results demonstrated that BMI was positively associated with serum levels of $\gamma$-tocopherol, and inversely associated with $25(\mathrm{OH}) \mathrm{D}$ and carotenoids, particularly pro-vitamin A carotenoids, suggesting possible influences of obesity on metabolism of these micronutrients. The differential association of BMI for the tocopherols and for pro- and non pro-vitamin A carotenoids also argues against generalized fat effects and oxidative effects alone as determinants of serum levels of these micronutrients.

Future epidemiologic studies of serum levels of lipid soluble micronutrients should consider obesity-related physiologic effects on circulating levels, in addition to dietary exposure in any analysis of their associations with disease risk.

\section{Acknowledgments}

The research was supported by the National Institutes of Health grants R03CA130061, S10RR020890, and R25CA90956. We would like to thank the committed study participants, the many staff members who assisted with the bean study over many years and the three dedicated summer students (Corey Kelsom, Brian Johnston, William Cooney) who assisted with the laboratory assays.

\section{Abbreviations}

$\begin{array}{ll}\text { BMI } & \text { Body mass index } \\ \text { CRP } & \text { C-reactive protein } \\ \text { 25(OH)D } & \text { 25-hycroxyvitamin D } \\ \text { HPLC } & \text { high performance liquid chromatography } \\ \text { ELISA } & \text { enzyme-linked immunosorbent assay } \\ \text { ANOVA } & \text { Analysis of variance }\end{array}$

\section{References}

1. Manson JE, Colditz GA, Stampfer MJ, Willett WC, Rosner B, Monson RR, et al. A prospective study of obesity and risk of coronary heart disease in women. N Engl J Med 1990;322:882-9. [PubMed: 2314422]

2. Colditz GA, Willett WC, Stampfer MJ, Manson JE, Hennekens CH, Arky RA, et al. Weight as a risk factor for clinical diabetes in women. Am J Epidemiol 1990;132:501-13. [PubMed: 2389754]

3. Renehan AG, Tyson M, Egger M, Heller RF, Zwahlen M. Body-mass index and incidence of cancer: a systematic review and meta-analysis of prospective observational studies. Lancet 2008;371:569-78. [PubMed: 18280327]

4. Suzuki K, Ito Y, Ochiai J, Kusuhara Y, Hashimoto S, Tokudome S, et al. Relationship between obesity and serum markers of oxidative stress and inflammation in Japanese. Asian Pac J Cancer Prev 2003;4:259-66. [PubMed: 14507248]

5. Coussens LM, Werb Z. Inflammation and cancer. Nature 2002;420:860-7. [PubMed: 12490959]

6. Andersen LF, Jacobs DR Jr. Gross MD, Schreiner PJ, Dale Williams O, Lee DH. Longitudinal associations between body mass index and serum carotenoids: the CARDIA study. Br J Nutr 2006;95:358-65. [PubMed: 16469154] 
7. Maetani M, Maskarinec G, Franke AA, Cooney RV. Association of leptin, 25-hydroxyvitamin D, and parathyroid hormone in women. Nutr Cancer 2009;61:225-31. [PubMed: 19235038]

8. Kamycheva E, Joakimsen RM, Jorde R. Intakes of calcium and vitamin d predict body mass index in the population of Northern Norway. J Nutr 2003;133:102-6. [PubMed: 12514276]

9. Garland CF, Garland FC, Gorham ED, Lipkin M, Newmark H, Mohr SB, et al. The role of vitamin D in cancer prevention. Am J Public Health 2006;96:252-61. [PubMed: 16380576]

10. Bardia A, Tleyjeh IM, Cerhan JR, Sood AK, Limburg PJ, Erwin PJ, et al. Efficacy of antioxidant supplementation in reducing primary cancer incidence and mortality: systematic review and metaanalysis. Mayo Clin Proc 2008;83:23-34. [PubMed: 18173999]

11. Brady WE, Mares-Perlman JA, Bowen P, Stacewicz-Sapuntzakis M. Human serum carotenoid concentrations are related to physiologic and lifestyle factors. J Nutr 1996;126:129-37. [PubMed: 8558292]

12. Bischoff-Ferrari HA, Giovannucci E, Willett WC, Dietrich T, Dawson-Hughes B. Estimation of optimal serum concentrations of 25-hydroxyvitamin D for multiple health outcomes. Am J Clin Nutr 2006;84:18-28. [PubMed: 16825677]

13. Le Marchand L, Hankin JH, Carter FS, Essling C, Luffey D, Franke AA, et al. A pilot study on the use of plasma carotenoids and ascorbic acid as markers of compliance to a high fruit and vegetable dietary intervention. Cancer Epidemiol Biomarkers Prev 1994;3:245-51. [PubMed: 8019375]

14. Parikh SJ, Edelman M, Uwaifo GI, Freedman RJ, Semega-Janneh M, Reynolds J, et al. The relationship between obesity and serum 1,25-dihydroxy vitamin D concentrations in healthy adults. J Clin Endocrinol Metab 2004;89:1196-9. [PubMed: 15001609]

15. Alemzadeh R, Kichler J, Babar G, Calhoun M. Hypovitaminosis D in obese children and adolescents: relationship with adiposity, insulin sensitivity, ethnicity, and season. Metabolism 2008;57:183-91. [PubMed: 18191047]

16. Maskarinec G, Takata Y, Franke AA, Williams AE, Murphy SP. A 2-year soy intervention in premenopausal women does not change mammographic densities. J Nutr 2004;134:3089-94. [PubMed: 15514280]

17. Stram DO, Hankin JH, Wilkens LR, Pike MC, Monroe KR, Park S, et al. Calibration of the dietary questionnaire for a multiethnic cohort in Hawaii and Los Angeles. Am J Epidemiol 2000;151:35870. [PubMed: 10695594]

18. Cooney RV, Franke AA, Wilkens LR, Gill J, Kolonel LN. Elevated plasma gamma-tocopherol and decreased alpha-tocopherol in men are associated with inflammatory markers and decreased plasma 25-OH vitamin D. Nutr Cancer 2008;60(Suppl 1):21-9. [PubMed: 19003577]

19. Franke AA, Custer LJ, Cooney RV. Synthetic carotenoids as internal standards for plasma micronutrient analysis by high-performance liquid chromatography. J Chromatogr B 1993;614:4357.

20. Methods for analysis of cancer chemo-preventive agents in human serum. Government Printing Office; Washington, DC: 1994. NIST special publication no. 874

21. Willett, W.; Stampfer, M. Implications of total energy intake for empidemiologic analyses. In: Kelsey, JL.; Marmot, MG.; Stolley, PD.; Vessey, MP., editors. Nutritional epidemiology. 2nd edition. Oxford University Press; New York: 1998. p. 273-301.

22. Ribeiro Nogueira C, Ramalho A, Lameu E, Da Silva Franca CA, David C, Accioly E. Serum concentrations of vitamin A and oxidative stress in critically ill patients with sepsis. Nutr Hosp 2009;24:312-17. [PubMed: 19721904]

23. Jiang Q, Ames BN. Gamma-tocopherol, but not alpha-tocopherol, decreases proinflammatory eicosanoids and inflammation damage in rats. FASEB J 2003;17:816-22. [PubMed: 12724340]

24. Jiang Q, Lykkesfeldt J, Shigenaga MK, Shigeno ET, Christen S, Ames BN. Gamma-tocopherol supplementation inhibits protein nitration and ascorbate oxidation in rats with inflammation. Free Radic Biol Med 2002;33:1534-42. [PubMed: 12446211]

25. Burnett, TSTY.; Harwood, PJ., et al. Mechanisms of phytochemical inhibition of carciogenesis: elucidating the role of $\gamma$-tocopherol in nutrition. In: Shibamoto, IT.; Terao, J.; Osawa, T., editors. Functional Foods for Disease Prevention. Amerian Chemical Society; Washington, DC: 1998. p. 45-58. 
26. Kull M, Kallikorm R, Lember M. Body mass index determines sunbathing habits: implications on vitamin D levels. Intern Med J 2009;39:256-58. [PubMed: 19402866]

27. Wortsman J, Matsuoka LY, Chen TC, Lu Z, Holick MF. Decreased bioavailability of vitamin D in obesity. Am J Clin Nutr 2000;72:690-3. [PubMed: 10966885]

28. Carlberg C. Lipid soluble vitamins in gene regulation. Biofactors 1999;10:91-7. [PubMed: 10609868]

29. Moro JR, Iwata M, von Andriano UH. Vitamin effects on the immune system: vitamins A and D take centre stage. Nat Rev Immunol 2008;8:685-98. [PubMed: 19172691] 
Table 1

Characteristics of study participants by ethnicity.

\begin{tabular}{llll}
\hline & Asians & Caucasians & All subjects \\
\hline $\mathrm{N}$ & 73 & 66 & 180 \\
Body mass index $\left(\mathrm{kg} / \mathrm{m}^{2}\right)$ & $24.7(23.7,25.7)^{*}$ & $27.1(25.4,28.8)$ & $26.3(25.4,27.1)$ \\
Age $($ year $)$ & $43.5(42.9,44.1)$ & $42.8(42.1,43.6)$ & $43.0(42.6,43.5)$ \\
Leptin $(\mathrm{ng} / \mathrm{mL})^{\dagger}$ & $11.8(10.1,13.9)^{*}$ & $17.6(14.4,21.5)$ & $14.7(13.2,16.6)$ \\
C-reactive protein $(\mathrm{mg} / \mathrm{L})^{\dagger}$ & $0.61(0.44,0.84)^{*}$ & $1.42(1.00,2.01)$ & $0.92(0.74,1.13)$ \\
$25(\mathrm{OH}) \mathrm{D}(\mathrm{nM})$ & $68.4(63.5,73.4)^{*}$ & $78.4(70.6,86.2)$ & $72.2(68.4,76.1)$ \\
$\alpha$-Tocopherol $(\mu \mathrm{g} / \mathrm{mL})$ & $14.4(12.9,15.9)$ & $13.2(11.7,14.7)$ & $13.6(12.7,14.4)$ \\
$\gamma$-Tocopherol $(\mu \mathrm{gg} / \mathrm{mL})$ & $1.6(1.4,1.9)$ & $1.7(1.5,1.9)$ & $1.7(1.5,1.8)$ \\
Pro-vitamin A carotenoids & & & \\
$\alpha$-Carotene $(\mathrm{ng} / \mathrm{mL})$ & $74.1(61.7,86.5)$ & $67.0(54.7,79.2)$ & $68.1(60.8,75.3)$ \\
$\beta$-Carotene $(\mathrm{ng} / \mathrm{mL})$ & $427(348,506)$ & $358(293,423)$ & $386(343,430)$ \\
$\beta-$-Cryptoxanthin $(\mathrm{ng} / \mathrm{mL})$ & $288(232,343)^{*}$ & $207(172,242)$ & $254(221,287)$ \\
$\quad$ Total pro-vitamin A carotnoids $(\mathrm{ng} / \mathrm{mL})$ & $789(671,906)^{*}$ & $632(536,728)$ & $708(639,777)$ \\
$\begin{array}{l}\text { Non pro-vitamin A } \\
\text { carotenoids }\end{array}$ & & & \\
$\quad \alpha$-Cryptoxanthin $(\mathrm{ng} / \mathrm{mL})$ & & & \\
$\quad \begin{array}{l}\text { Lycopene }(\mathrm{ng} / \mathrm{mL}) \\
\text { Trans lutein }(\mathrm{ng} / \mathrm{mL})\end{array}$ & $48.8(42.8,54.7)^{*}$ & $39.5(36.3,42.6)$ & $43.4(40.5,46.2)$ \\
$\quad$ Total non pro-vitamin A carotenoids $(\mathrm{ng} / \mathrm{mL})$ & $1133(1041,1225)^{*}$ & $1001(924,1077)$ & $1049(997,1100)$ \\
\hline
\end{tabular}

Values are presented as mean (95\% confidence interval for mean).

* $\mathrm{P}$ value $<0.05$ (Student's t-test) for comparison to Caucasians.

${ }^{\dagger}$ Geometric mean and $95 \%$ confidence interval for geometric mean. Log transformed value were used for P-value. 


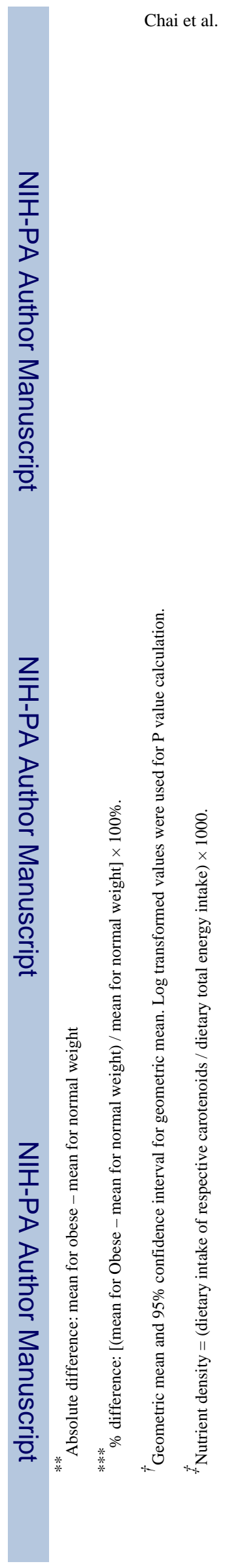

Page 10

Nutr Res. Author manuscript; available in PMC 2011 April 1. 